\title{
Impact of chitin synthesis inhibitor on brown planthopper (BPH), Nilaparvata lugens (Stal.) and gundhi bug, Leptocorisa acuta (Thunberg) in rice
}

\section{SANDEEP CHAUDHARY AND M. RAGHURAMAN*}

Department of Entomology and Agricultural Zoology, Institute of Agricultural Sciences, Banaras Hindu University, VARANASI (U.P.) INDIA

\section{ARITCLE INFO}

$\begin{array}{ll}\text { Received } & : 10.06 .2014 \\ \text { Revised } & : 06.08 .2014 \\ \text { Accepted } & : 21.08 .2014\end{array}$

KEY WORDS :

BPH, Gundhi bug, Buprofezin, Rice

*Corresponding author:

Email:raghu_iari@yahoo.com

\begin{abstract}
An experiment was conducted during Kharif season of 2012, at the Agricultural Research Farm of Banaras Hindu University, Varanasi to evaluate the efficacy of chitin synthesis inhibitor, buprofezin in combination with acephate at different doses against the brown plant hopper and Gundhi bug in rice ecosystem. The treatments were sprayed thrice after transplanting. Results showed that among all the treatments, Buprofezin 15 per cent + Acephate 35 per cent WP was most effective against both the sucking pests and conversely protected the crop. When applied at $1500 \mathrm{ml} / \mathrm{ha}$, the mixture significantly suppressed the population of BPH to 3.89 per 5 hills and gundhi bug to 1.66 per five sweeps. It also significantly increased the yield of rice $(57 \%)$ over untreated control.
\end{abstract}

How to view point the article : Chaudhary, Sandeep and Raghuraman, M. (2014). Impact of chitin synthesis inhibitor on brown planthopper (BPH), Nilaparvata lugens (Stal.) and gundhi bug, Leptocorisa acuta (Thunberg) in rice. Internat. J. Plant Protec., 7(2) : 369-372. 